\title{
Are state-local government expenditures converging? New evidence based on sequential unit root tests
}

\author{
Saeid Mahdavi ${ }^{1}$ - Joakim Westerlund ${ }^{2,3}$
}

Received: 19 May 2015 / Accepted: 7 June 2016 / Published online: 18 August 2016 (C) The Author(s) 2016. This article is published with open access at Springerlink.com

\begin{abstract}
Large and persistent gaps in subnational public expenditure have important implications regarding growth, equity, and migration. In this context, we revisit the question of expenditure convergence across the American states to provide more nuanced evidence than found by a small number of previous studies. We employ a methodology due to Smeekes (Bootstrap sequential tests to determine the stationary units in a panel, 2011) that sequentially tests for unit roots in pairwise (real per capita) expenditure gaps based on user specified fractions. In a panel of 48 combined state-local government units (1957-2008), we found that expenditures on highways, sanitation, utility, and education were far more convergent than expenditures on health and hospitals, police and fire protection, and public welfare. There was little evidence of "club convergence" based on the proportion of intraregional convergent pairs. Several historically high-grant receiving states showed relatively strong evidence of convergence. Our results bode well for future output convergence and opportunities for Tiebout-type migration across jurisdictions. They also imply a diminished role for public infrastructure and education spending in business location choices over time and a mixed role for federal grants in inducing convergence.
\end{abstract}

Keywords State and local governments - Regional economics · Convergence · Sequential unit root tests

JEL Classification $\mathrm{H} 72 \cdot \mathrm{C} 33$

Joakim Westerlund joakim.westerlund@nek.lu.se

1 The University of Texas at San Antonio, One UTSA Circle, San Antonio, TX 78249, USA

2 Lund University, P.O. Box 7082, 22007 Lund, Sweden

3 Centre for Financial Econometrics, Deakin Business School, Deakin University, 221 Burwood Highway, Burwood, VIC 3125, Australia 


\section{Introduction}

In the past few decades, the US system of fiscal federalism has witnessed a process of devolving some federal responsibilities to the state and local governments (SLGs) coupled with growing federal grants to SLGs to support their expanded role. A major outcome of this process, characterized as "devolution evolution" with the federal government as the "dominant senior partner," has been a dramatic growth in SLG expenditures. ${ }^{1}$ Baicker et al. (2012) document this growth in SLG total expenditure and its components (relative to GDP) over the period 1952-2006. ${ }^{2}$ After analyzing the effects of federal grants, fiscal competition, mobility, voting patterns, and demographic and income trends that might have explained the observed data patterns, the authors draw an intriguing conclusion: "...much of the growth in state budgets has been driven by intergovernmental interactions. Restricted federal grants to states have increased, and federal policy and legal constraints have also mandated or heavily incentivized state own-source spending, particularly in the areas of education, health and public welfare" (p. 1079).

Studies of trend in the level of SLG expenditures may shed light on perhaps a more interesting question concerning the evolution of the spatial distribution of these expenditures. After all, federal grants and other factors that might have been driving the growth in SLG expenditures can also explain changes in their spatial distribution to the extent that they exert differential growth effects across SLG units. However, whether or not such distribution has evolved in a way that (real per capita) expenditures across states are actually converging cannot be ascertained from studies of expenditure size.

The question of expenditure convergence is an important one for several interrelated reasons. Firstly, large public expenditure gaps across SLGs that persist over time are inconsistent with the objective of narrowing cross-state fiscal disparity that is considered as a "widely embraced goal" in the context of a federalist form of government (Yilmaz et al. 2006). While fiscal equalization programs have not been formally adopted in the USA, many federal policies and grant restrictions are intended to effectively exert a leveling effect on SLG expenditures. ${ }^{3}$ Therefore, it is worth exploring whether, after several decades of federal fiscal activism, there is also evidence of expenditure convergence consistent with federal policies. Secondly, there is a large body of literature, motivated by Barro's (1990) paper, suggesting that the composition of public expenditures has important growth implications. "Productive" public expenditures (infrastructure, R\&D, and human capital, for example) are argued to be "growth enhancing" as they generate positive externalities to private firms, complement private

\footnotetext{
1 See Nathan (1996), Tannenwald (1998) uses these terms in relation to the schizophrenic nature of the devolution process in the context of his analysis of the Balanced Budget Act of 1997. However, as demonstrated by the Affordable Care Act of 2010, these terms aptly describe an important feature of the US fiscal federalism since then.

2 The authors report that "Local direct spending increased from 5.8 to $10.6 \%$ of GDP during this period, with most of this growth occurring before the 1970s. In contrast, state direct spending increased steadily over this period, rising almost threefold from $3.1 \%$ of GDP in 1952 to $8.6 \%$ in 2006" (p. 1080).

3 The "general revenue sharing program" instituted by the federal government during 1972-1986, for example, disbursed unrestricted funds to subnational (local) governments and had mild equalizing features. Like some grants today, it took personal income into account.
} 
investments and/or improve their productivity. "Nonproductive" public expenditures (also referred to as "social welfare/protection"), on the other hand, tend to mainly redistribute income. While these expenditures are generally viewed as "growth retarding", they are important from an equity perspective. Accordingly, it matters which category of public spending is spatially converging, if at all. Thirdly, large and persistent public expenditure gaps may be detrimental to broad-based economic prosperity, social harmony, and national cohesion. If left unaddressed, they may ultimately require more radical policy interventions than would have otherwise been necessary. Finally, as argued by Scully (1991), spatial convergence of fiscal regimes diminishes the opportunity for "Tiebout-type migration" (Tiebout 1956) according to which citizen-voters migrate to jurisdictions with public benefit-tax packages that best match their preferences. Thus, to the extent that net in-migration to the generally low tax-low spending states of the South (originating especially from the high tax-high spending states of the Northeast and California) in the past several decades was fiscally motivated, one would expect a slowdown in this pattern of interstate migration as spending spatially convergences over time.

In addition to federal (grant) policies, the confluence of a number of other forces may drive expenditure convergence. These include economic integration, interjurisdictional fiscal competition, factor mobility, globalization (trade) related pressures, and "yardstick competition" induced by geographic proximity. On the other hand, differences in voter preferences and heterogeneity in political and fiscal institutions across jurisdictions tend to moderate the influence of these leveling forces. If powerful and persistent, they may slow down the speed of convergence in some jurisdictions enough to cause divergence in the long run. Such divergence may be reinforced by Tiebout migration to the extent that fiscally induced migration is significant. Assessing the net effect of these forces is further complicated by the fact that they interact. For example, federal grants may influence fiscally motivated migration decisions and ideological orientations and political considerations may affect the growth rates of different SLG expenditure categories that are supported by federal grants and/or own-source revenues.

The empirical literature on fiscal convergence at the US subnational level, unlike that on subnational output level, is quite small. In one of the earliest studies of this kind, Scully (1991) hypothesizes that if income per capita levels and income distributions converge spatially, then tax regimes will converge spatially too. He finds supporting " $\beta$ convergence" evidence (a negative relationship between the rate of growth of a variable and its past level) for this hypothesis over the period 1960-1980. The convergence in expenditures is not directly tested by the author but is implied: "...increased equality of income increases the rate of taxation and hence the size of the public sector" (p. 57). Fisher and Navin (1992) find that the interstate narrowing of per capita spending was less and the variation in the effective tax rates (own-source revenue-income ratio) was more than what would have been expected based on changes in state population, income, grants, and other factors. They conclude that intestate fiscal variations reflect "real desires" and, in view of significant difference in underlying preferences and perspective, "interstate competition will not and should not eliminate interstate fiscal differences" (p. 477). 
Kenworthy (1999) assesses whether " $\sigma$-convergence" (a declining coefficient of variation over time) materialized among the fifty American states in the context of several decades of US economic integration. His fiscal variables include state taxoutput ratio and real benefit level of Aid to Families with Dependent Children (AFDC). He presents CV values for 1970, 1980, 1990, and 1996 and concludes that there were not significant declines in the CVs for either of the two variables. More generally, however, he concludes that there is little support for the leveling effect of economic integration. This is mainly attributed to "...the space for variation permitted by market competition and to the importance of economic institutions in mediating the impact of market forces" (p. 867).

Annala (2003) tests for (conditional) $\beta$-convergence and $\sigma$-convergence of per capita real output and several tax and expenditure categories among SLGs over the period 1977-1996. With few exceptions, his findings generally support convergence in the fiscal variables. The exception on the spending side is the health and hospitals category. In a similar study, Skidmore and Deller (2008) report results consistent with $\beta$-convergence in relation to several municipal expenditure categories in Wisconsin over the period 1990-2000. Coughlin et al. (2007) contribute to the $\beta$-convergence literature by employing a more sophisticated approach. They incorporate three alternative "spatial weight" matrixes that account for the effects of "spatial interdependence" on fiscal policy and output paths across states. In a panel of 48 contiguous states during 1977-2002, they find rather consistent evidence of $\beta$-convergence for real per capita total, education, highway, and public welfare, but not for health and hospitals expenditures. This finding is corroborated by the evidence from $\sigma$-convergence between 1977 and 2002.

Annala and Chen (2011), however, examine fiscal convergence using a stochastic approach. They employ two tests to detect presence of a unit root in real per capita levels of general, education, health and hospitals, and highway expenditures in a panel of 48 contiguous states over the period 1977-2000. Their results reject the null hypothesis of a unit root, implying convergence, for all the variables with the exception of the health and hospitals and public welfare categories. Finally, as a corollary to their study of state government size, Baicker et al. (2012) calculate CVs for spending categories at 5-year intervals between 1957 and 2002. The CVs do not show systematic changes in dispersion for the categories other than for health and hospitals (mostly rising) and public welfare (mostly falling).

A major drawback common to the methodologies employed in previous studies is the "all-or-none" nature of the evidence they produce. ${ }^{4}$ That is, acceptance or rejection of the convergence hypothesis is an inference made for all the panel members. ${ }^{5}$ Thus, the possibility that only a fraction of the panel may be converging is ruled out. This can lead to conclusions based on unwarranted generalizations. In this paper, we seek to empirically examine two major questions motivated by the above discussions: One, is

4 Other limitations include the fact that that $\beta$-convergence is uninformative about a distribution's dynamics as it captures only a "representative" economy's dynamics (Quah 1996). Moreover, $\beta$-convergence is a necessary, though not sufficient condition for $\sigma$-convergence. See Islam (2008) for a formal proof.

5 Strictly speaking, the IPS (Im et al. 2003) test used by Annala and Chen (2011) tests the null of individual unit root against the alternative that a nonzero fraction of the panel is stationary. However, the authors make inferences about the whole panel. 
there evidence of expenditure convergence at the SLG level? Two, if so, in which SLG unit(s) and in relation to what expenditure category the evidence is more pronounced? To this end, we examine the data on per capita real total expenditure and several of its economic and functional (sub)categories for a panel of 48 combined state-local government units over a period spanning five decades (1957-2008). We substantially depart from previous studies by employing a novel stochastic methodology referred to as the "bootstrap sequential quantile test" (BSQT) of unit roots in all possible pairwise expenditure gaps. This methodology, proposed by Smeekes (2011), has several advantages over conventional panel unit root tests applied to levels. Firstly, is it particularly well-suited for the task at hand as it allows for sequential testing of the null hypothesis of nonstationary (or divergent) pairwise gaps based on user specified fractions. As such, rejection (or non-rejection) of the null does not apply to the entire panel, but to the specified fraction at each stage. In panels with relatively small $\mathrm{N}$, the fraction can be selected in a way that allows one to identify individual convergent gaps within the panel. Secondly, it avoids the problem of controlling for the size of the test as in multiple testing. Thirdly, the use of all possible pairwise gaps implies that our results are not sensitive to the choice of a benchmark for defining gaps (Pesaran 2007). Finally, a narrowing of the pairwise gaps does not imply that all SLG expenditure levels are converging to the same steady-state level as in "unconditional" $\beta$-convergence tests; but rather a reduction in the overall spatial expenditure dispersion. ${ }^{6}$

The rest of this paper proceeds as follow. Section 2 briefly discusses some of the forces that potentially drive spending convergence (divergence) and some interactions among them. Section 3 outlines the empirical methodology of the paper based on BSQT. Section 4 presents three sets of results corresponding to three levels of aggregation: the full panel, regional groups, and individual SLG unit. The last section summarizes the findings and discusses their implications.

\section{State-local government expenditure convergence}

This section draws from several strands of research to identify some of the factors that may affect the spatial distribution of public expenditures by narrowing (or widening) expenditure gaps over time.

\subsection{Economic "laws" and relationships}

At a fundamental level of analysis, as noted by Skidmore and Deller (2008), government expenditures are subject to the law of diminishing returns. On the supply side, the marginal product of public (capital) spending diminishes at higher levels of spending. On the demand side, the marginal utility of government provided goods and services also diminishes at higher levels of consumption. This implies that, all else being equal, high-spending SLGs should have less incentive to further spend on some categories and their citizens should have less willingness to pay for them as

6 We thus avoid confusing "catch up" with "homogenization" which happens when some lowspending/poor SLGs narrow their spending gaps with high-spending/rich states, while, at the same time, the gaps within the low-spending states themselves are widening (Kenworthy 1999). 
additional expenditures and payments would yield "less bang from the buck."7 The opposite holds true in low-spending SLGs. Accordingly, the higher (lower) the level of present spending, the lower (higher) will be its rate of future growth. This growth rate differential is expected to drive convergence over time.

Spatial convergence in SLG spending, however, may simply reflect spatial convergence of output. The latter is a fundamental proposition of the "neoclassical growth model" (Solow 1956). ${ }^{8}$ If one is willing to further assume that expenditures are a constant proportion of (lagged) output, then output convergence should result in convergence of expenditures; albeit at a different speed. ${ }^{9}$ This assumption, however, is challenged by Wagner's Law (1893), which states that the (relative) size of the public sector increases with per capita income reflecting increases in "social activities," 'administrative and protective actions," and "welfare functions" of the state (Musgrave 1969). Peacock and Scott (2000) and Peacock (2006) claim that their reading of Wagner's original works suggests that "state activities" encompass more specific areas such as public utilities and enterprises, public provision of health and educational services, and a social system of security. The implication is that the change in the expenditure-output ratio may be category specific. ${ }^{10}$ Importantly, to the extent that the ratio systematically varies with per capita income, expenditure convergence may not result from output convergence.

Another theoretical possibility is divergence in output which, as proposed by "New Growth Theory" (see, for example, Romer 1986), can result if spillovers associated with abundant capital and/or skilled labor in some economic units put them on limitless growth paths. In this case, spending convergence will not result even if spending is a stable proportion of the output.

\subsection{Federal intergovernmental transfers ("grants")}

During the past half-a-century, there has been an explosion of federal grants to SLGs accompanying the devolution process. ${ }^{11}$ Several interrelated aspects of the grants

\footnotetext{
7 We wish to stress that more public spending is not necessarily associated with quantitatively and qualitatively superior set of outcomes. Therefore, the frequently employed spending measures may be a rough proxy for spending outcomes such as output actually produced and/or benefits actually received.

8 The model postulates that under the assumptions of diminishing marginal productivity of capital, capital mobility and technological diffusions, output (per worker) across jurisdictions converges to the same steadystate level ("unconditional /absolute convergence").

9 Annala (2003) and Skidmore et al. (2004) incorporate this assumption into the neoclassical growth model to test for $\beta$-convergence in public spending and/or taxes. Annala's (2003) conditional $\beta$-convergence results indicate that real per capita state general expenditures and tax revenues converged at a rate more than twice that of state output. Spatial models estimated by Coughlin et al. (2007), however, suggest that total expenditures converged faster and tax revenues converged slower than output.

10 In this connection, Mahdavi (2011) reports that during the period 1957-2006 the ratio of SLG highway expenditures to GDP actually fell while the corresponding ratios for police and fire protection, education, and utility remained roughly constant. On the other hand, insurance trust benefits, public welfare, financial administration and general control, and interest on general debt categories (significantly) gained in terms of their GDP shares.

11 According to the Census Bureau data, the ratio of federal grants to SLGs total (own-source) revenue went up from 8.4 (9) \% in 1957 to over 18 (22)\% in 2008 and has been rising since then.
} 
are worth noting in relation to the link between grants and expenditure convergence. Firstly, as part of its redistributive function, the federal government allocates grants to state governments, and to local governments through state-to-local grants, to ease the burden of low fiscal capacity and reduce the extent of fiscal disparity across jurisdictions. ${ }^{12}$ In reality, the federal grants to state governments explicitly and formally designated for "fiscal equalization" are rather insignificant although many grants from state governments to local jurisdictions, (such as education grants to school districts) have a significant explicit equalizing component (Oates 1999). However, federal grants to states, which mainly focus on a wide variety of specific functions or programs, are allocated based on formulas that may have an equalizing feature. ${ }^{13}$

Secondly, federal grants affect the policy priorities of SLGs by altering their incentive structure and encouraging them to implement programs that are consistent with national priorities and/or meet certain national standards (CBO 2013). Aside from (unfunded) federal mandates and regulatory requirements, the literature suggests several channels through which grants may achieve these objectives. Grants with matching requirements, for example, are intended to ensure cost sharing by SLGs. However, by lowering the perceived marginal cost or "tax price" of providing goods and services to SLGs, these grants also stimulate more spending by SLGs out of their own-source revenues. Expenditure convergence may result as a byproduct of this "price effect." In this connection, Baicker et al. (2012, p. 1089) point out that "Matching grants clearly promote higher spending, and the progressivity of the federal match may reduce heterogeneity if it increases spending disproportionately in low-spending states." Federal grants also increase the resources available to SLGs and, all else being equal, their spending. A side effect of this "income effect" is a reduction in the extent and scope of intergovernmental competition which acts as a constraint on expansion of SLG budgets (McKenzie and Staff 1978). The impact of grants on SLG expenditures, however, may be indirect. Holcombe and Stroup (1996), for example, find that federal grants have a systematic positive (and asymmetric) effect on the income elasticity of SLG expenditures.

Thirdly, on theoretical grounds, all federal grants are not expected to affect SLGs expenditures in the same way. Gramlisch and Galper (1973), for example, argue that open-ended matching grants (like Medicaid grants) lower the relative prices of the aided areas and, if the demand for the aided areas is price elastic, increase the recipient government expenditures by more than the grants. Close-ended lump-sum grants, on the other hand, are unrestricted and do not change the relative prices. If both public and private goods have positive income elasticities, such transfers can stimulate the recipient government expenditures and lower taxes by some. Close-ended categorical grants (which apply to most federal programs) are transfers to be used for specific pro-

\footnotetext{
12 Yilmaz et al. (2006, p. 11) note two normative considerations as the primary source of concern about fiscal disparity: "First, access to some minimum level of state and local public services is desirable. Second, as long as fiscal disparity exists, residents of states with higher capacity bear a lower tax burden to obtain this minimum than residents in states with lower fiscal capacity."

13 The bulk of federal grants have been allocated to health, income security, education, transportation, and housing and community services (CBO 2013). The fastest-growing category is health reflecting primarily the growth of Medicaid. The federal match rates for Medicaid grants are inversely related to state per capita personal income.
} 
grams and their stimulative effect lie somewhere between the other two types of grants. However, they can be more stimulative than the open-ended matching grants, if they come with the additional restriction of being limited to incremental expenditures that exceed a base amount or "maintenance level." Accordingly, the expenditure response of SLGs to federal grants is affected by the composition of grants received. ${ }^{14}$ It also depends on whether substitutions among federally supported programs are possible and coverage overlap exists (Chernick 2000).

Given the variety of grant types and the programs they support within each expenditure category the overall effect of grants on the category's convergence is rather ambiguous. From the perspective of spending convergence (divergence), federal grants, regardless of whether they supplement or supplant SLGs own expenditures (or provide an opportunity to lower taxes), matter so long as they exert differential expenditure growth effects across SLGs.

\subsection{Mobility and interjurisdictional (fiscal) competition}

Interjurisdictional competition has been defined as is "the manner in which the free movement of goods, services, people and capital constrains the actions of independent governments in a federal system" (ACIR 1991, p. 10). A number of models have been developed emphasizing different modes of this competition (see Kenyon 1997). The Tiebout (1956) model, for example, emphasizes the role of individuals who, through migration, sort themselves across jurisdictions that offer the public servicetax bundles that best match their preferences. In this context, relatively high tax rates in a jurisdiction may drive away taxpayers while generous welfare benefits may attract “welfare migrants" from other jurisdictions. Oates and Schwab's (1988) model stresses competition among jurisdictions to attract (and retain) mobile capital by offering low taxes and providing, presumably superior, "public inputs" like educated workforce and infrastructure to firms. Accordingly, to the extent that skilled labor and capital are mobile the threat of their migration acts as a disciplining device in relation to the fiscal behavior of local governments. The "exit mechanism" central to these models is replaced by the "voice mechanism" in the "yardstick competition" model of Besley and Case (1995). Here, voters in a state judge the fiscal decisions of their elected officials using those made by officials in other (nearby) states as a yardstick.

A major insight of the above models is that the fiscal actions of jurisdictions are interdependent. What are the implications of such interdependence for expenditure

\footnotetext{
14 It should be noted that the theoretical models that are based on budget (as opposed to utility) maximization hypothesis suggest that the stimulative effect of grants do not depend on the exact grant type. In particular, they reject the prediction of the conventional models that the stimulative effect of lump-sum grants (which do not have a price effect) is the same as the effect of an equivalent change in private income. In fact, many empirical studies find the marginal propensity to spend out of lump-sum grant funds is much larger than that out of private income. This nonequivalence is dubbed as the "flypaper effect" to underline the point that grant fund "sticks where it hits." An implication of this effect is that nonmatching grants tend to remain in the subnational government sector instead of being transferred to the private sector in the form of tax cuts. See, for example, Fisher (1982), Hines and Thaler (1995), Holcombe and Stroup (1996), Brooks and Phillips (2010), and Dahlby and Ferede (2014) for reviews of theory and evidence, alternative explanations of the flypaper effect, and original references.
} 
convergence? According to Tiebout sorting, people vote with their feet to reveal their preference for a different fiscal bundle than what they received before. This desire for fiscal heterogeneity or differentiation is expected to reinforce existing differences in fiscal regimes that run against convergence. ${ }^{15}$ On the other hand, some states may feel compelled to become more fiscally similar to other states due to yardstick competition, or as they try to "keep up with the Joneses." 16 Shannon (1989) suggests that both interstate competition and comparison set upper and lower bounds on state fiscal decisions and behavior and, thus, act as a stabilizing factor.

The following points are worth noting. Firstly, the extent of yardstick competition may be category specific (see footnote 20). Secondly, grants may interfere with the process of output (and expenditure) convergence through factor mobility and interjurisdictional competition. This happens if grants slow down factor mobility, attenuate its equilibrating effect on factor prices, and diminish its disciplinary effects through the "exit mechanism." Also, grants may change spending composition in favor of "nonproductive" expenditures and thus undermine the process of income convergence. ${ }^{17}$ Thirdly, one would expect that fiscal interdependence (competition and comparison) to be more intense among states that belong to a "club" whose members are similar with respect to some characteristics. Convergence among club member states may result, because each state is arguably more sensitive to the policies of other states that are more similar to it than less so. One such characteristic is geographic proximity of states belonging to the same region. ${ }^{18}$ However, fiscal interdependence may characterize interaction among states that may not be geographically contiguous or proximate (Case et al. 1993). Studies of interstate fiscal spillovers, therefore, employ different spatial measures of "neighborliness," to construct "weights matrices" that account for fiscal dependence. ${ }^{19}$ Finally, fiscal interdependence may have a global dimension to the extent that competition for mobile international capital affects state decisions in relation to the size and composition of expenditures.

15 The Tiebout model is based on fairly strong assumptions including perfect information and cost free migration. It may be less relevant to states than localities (Boadway and Tremblay 2012; Baicker et al. 2012).

16 For empirical evidence on yardstick competition see Case et al. (1993) and Baicker (2005), for example.

17 See Cyrenne and Pandey (2015) for the effects of fiscal equalization on the composition of government expenditures and growth in the context of Canadian provinces.

18 Such states may be relatively homogeneous in relation to their historical background, economic structure, as well as social, political and cultural characteristics. This reflects "the first law of geography" which states that "Everything is related to everything else, but near things are more related than distant things" (Tobler 1970).

19 Case et al. (1993) find evidence of state expenditure interdependence to be stronger when "neighborliness" is defined based on similarity in racial composition. Coughlin et al. (2007) report results suggesting that income and/or demographic similarities were more important in relation spatial correlations of expenditure growth rates with two exceptions: education (for which contiguity mattered more) and health and hospitals (for which no evidence was found). Baicker (2005, p. 541) notes that "We might expect different types of spending to be more sensitive to neighbors' spending than others. There may be more yardstick competition in administrative spending or public safety, or there may be greater fear of recipient immigration in social services spending...States may look to geographic neighbors to judge transportation expenses, while looking to states where residents move to or from when concerned with being a welfare magnet." She finds that the degree of interstate population mobility performs relatively better in capturing spillover effects among states in relation to Medicaid spending. 


\subsection{Political and fiscal institutions}

Government total spending and its composition and growth rate are affected by a wide array of actors that interact within political and fiscal institutions. These actors include citizen-voters, interest groups, lobbying organizations, elected officials, and bureaucrats who act based on self-interest. Political parties, presumably reflecting citizen-voters' ideology and expectations regarding the role of government and scope of its responsibilities, determine the partisan balance of the legislative and the executive branches of the government. The latter, in turn, affects the allocation of funds among competing needs through setting budget priorities and imposing fiscal constraints in the form of gubernatorial veto power, balanced budget requirements, tax and expenditure limits (TELs), and/or debt limits. Actors both inside the government (bureaucrats) and outside of it (interest groups and lobbyists) influence the development of budget to varying degrees. Moreover, citizen-voters may directly express their preferences for certain publicly funded projects and programs through initiatives and referenda.

These actors and institutions play a vital role in the process of political mediation between forces that exert a leveling effect on government expenditures and actual outcomes of the budget process. Political entrepreneurs may find it beneficial to fund and expand some programs, through federal grants or own revenues, if the programs enjoy strong support from the public or various lobbies and/or are perceived as "developmental." On the other hand, they may limit or cut funds to programs that are politically contentious, not backed by active and powerful constituencies, and/or perceived as "redistributive" in nature. ${ }^{20}$ However, public preferences, the partisan balance of power in government, institutional configurations, and what is viewed as both fiscally feasible and politically acceptable vary across states and localities. Spatial variations in these factors may, in turn, lead to policy variations, distinct response patterns, and path dependency in fiscal matters. ${ }^{21}$ These variations counter the forces that drive expenditure convergence and, if persistent and rigid enough, they may even cause divergence.

Finally, states differ with respect to the proportion of total state-local government expenditure that is controlled by local governments. Since there are numerous local

\footnotetext{
20 The following findings from a study of state welfare spending commissioned by the Department of Health and Human Services (The Lewin Group 2004; p. ES.4) illustrate the role of some of the factors noted above in funding various programmatic spending categories: "Choices affecting cash assistance spending seemed to be more influenced by the ideological views of elected officials. By contrast, Medicaid policies and expenditures were, especially in the rural southern states, strongly affected by the active political involvement of service providers, federal match rates, and federal mandates. Together, these factors have helped to sustain Medicaid spending in poor states despite recent fiscal pressures to cut expenditures. Finally, non-health social services were typically of low political salience and administrators were often given significant discretion over how to allocate funds across different services. State resources, increasing program flexibility (partly attributable to the TANF block grant), and executive priorities seemed more important in determining how much spent on these non-health services and which services were funded and which were not." (Emphases added). See also related studies by Volden (1999) and Bailey and Rom (2004).

21 For example, the "price effect" of matching grants may depend on state-specific factors and characteristics.
} 
governments making spending decisions based on local needs, preferences and revenue capacity that vary significantly across localities, expenditure categories that are characterized by a large local government share are expected to be less convergent than those with a large state government share. The discussions above suggest that forces that may drive expenditure convergence (or divergence) (a) are varied ranging from policy variables to globalization, (b) have effects on public expenditures that are modified as they go through political and institutional filters, (c) affect different expenditure categories differently, and (d) tend to interact with one another. We next turn to our empirical methodology to assess the net effects of these factors on expenditures conversion.

\section{Empirical methodology}

\subsection{Sequential unit root tests}

We define convergence in terms of narrowing pairwise expenditure gaps. To put our methodology in proper context, we begin by describing the pairwise convergence concept of Pesaran (2007). Suppose, therefore, that the log expenditure for the ith SLG unit in year $\mathrm{t}$, denoted by $\mathrm{e}_{i, t},(i=1, \ldots, N$ and $t=1, \ldots, T)$, is nonstationary. Then, a pairwise convergence is said to occur if, for any pair of SLGs $(i=1, \ldots, N-1$ and $j=i+1, \ldots, N)$, the expenditure gap $\mathrm{g}_{i j, t}=\mathrm{e}_{i, t}-\mathrm{e}_{j, t}$ is stationary; thereby ruling out both deterministic and stochastic trends. Thus, not only should $\mathrm{e}_{i, t}$ and $\mathrm{e}_{j, t}$ be cointegrated with cointegrating vector $(1,-1)$, but they should also be cotrending. This definition is very flexible as it allows the two units to have different initial endowments, saving rates, or rates of population growth (Pesaran 2007). Moreover, gaps are not defined as deviations from an arbitrarily selected benchmark.

A typical approach to testing for convergence is to subject $g_{i j, t}$ to a panel unit root test, which would then be testing the null hypothesis of divergence against the alternative of convergence for at least some expenditure pairs. The problem here is that while the null hypothesis can certainly be formulated as that all the pairs are divergent, the alternative hypothesis is too broad for any interesting economic conclusions; it could be that all the pairs are converging, but it could also be that there is only a small fraction of pairs that converges. It is therefore important to consider methods that can provide more information than just a rejection or non-rejection for the whole panel. Pesaran (2007) take one step in this direction and suggest performing individual unit root tests on each series and then estimating the proportion of stationary gaps in the panel. The main drawback with this approach is that the estimated proportion is only valid under the null hypothesis of a unit root. Also, the approach does not allow one to infer whether that estimate is statistically different from the true proportion. Recent studies have developed methods to estimate proportion of stationary gaps more generally. One such method is the bootstrap sequential quantile test (BSQT) approach of Smeekes (2011). The advantages of BSQT are that it can be used to estimate the proportion of stationary gaps and identify the SLGs for which convergence holds. Also, BSQT is one of the most general approaches available in that it allows for very unrestricted forms of serial and cross-sectional dependence. 
Our purpose is to estimate the proportion of convergent SLG expenditure pairs or q. Let us, therefore, denote by $q_{1}, \ldots, q_{K}$ the quantiles to be considered in the BSQT approach. The number of convergent SLGs corresponding to $q_{k}$ is given by $c_{k}=\left\lfloor q_{k} K\right\rfloor$, where $\lfloor x\rfloor$ denotes $x$ rounded to the nearest integer. Let $H_{0}\left(q_{k}\right)$ denote the null hypothesis that the a proportion $q_{k}$ of all SLG expenditure pairs is convergent (or equivalently, that $c_{k}$ out of the $M=N(N-1) / 2$ pairs are convergent), $H_{1}\left(q_{k+1}\right)$ denote the alternative hypothesis that at least a proportion $q_{k+1}>q_{k}$ of the pairs is convergent, and $\tau\left(q_{k}, q_{k+1}\right)$ be a test statistic for testing $H_{0}\left(q_{k}\right)$ versus $H_{1}\left(q_{k+1}\right)$. The sequential testing procedure is described as follows.

\subsection{Search algorithm}

1. Test $H_{0}\left(q_{1}\right)$ against $H_{1}\left(q_{2}\right)$.

2. If $H_{0}\left(q_{1}\right)$ is not rejected, set $\hat{q}=q_{1}$. If $H_{0}\left(q_{1}\right)$ is rejected, test $H_{0}\left(q_{2}\right)$ against $H_{1}\left(q_{3}\right)$.

3. Keep testing until $H_{0}\left(q_{k}\right)$ cannot be rejected anymore, and set $\hat{q}=q_{k}$. If all null hypotheses up until and including $H_{0}\left(q_{K}\right)$ are rejected, set $\hat{q}=1$.

As Smeekes (2011) shows, the above procedure is asymptotically (as $T \rightarrow \infty$ ) valid in the sense that the probability of ending up with a too low or too high estimate is zero. Hence, if we denote the significance level of the test by $\alpha$, then we have that

$$
\lim _{T \rightarrow \infty} P(\hat{q}=q)=1-\alpha
$$

As for the construction of $\tau\left(q_{k}, q_{k+1}\right)$, let us denote by $\theta_{i j}$ the individual unit root test statistic when applied to $g_{i j, t}$. Let us further denote by $\theta_{(1)} \leq \ldots \leq \theta_{(M)}$ the order statistics associated with $\theta_{i j}$. The test statistic to be used in the search algorithm is given by the order statistic corresponding to the alternative hypothesis to be tested, that is,

$$
\tau\left(q_{k}, q_{k+1}\right)=\theta_{(c k+1)} .
$$

The particular unit root test statistic considered in this paper is a version of the union of rejections (UR) statistic proposed by Smeekes and Taylor (2012) and can be written as

$$
\theta_{i j}=\min \left\{\mathrm{c}_{1} \mathrm{ADF}-\mathrm{OLS}_{i j}^{\mu}, \mathrm{c}_{2} \mathrm{ADF}-\mathrm{GLS}_{i j}^{\mu}, \mathrm{c}_{3} \mathrm{ADF}-\mathrm{OLS}_{i j}^{\tau}, \mathrm{c}_{4} \mathrm{ADF}-\mathrm{GLS}_{i j}^{\tau}\right\} \mathrm{GLS}_{i j}^{\mu},
$$

where $\mathrm{ADF}-\mathrm{OLS}_{i j}^{\mu}$ and ADF $-\mathrm{GLS}_{i j}^{\mu}\left(\mathrm{ADF}-\mathrm{OLS}_{i j}^{\tau}\right.$ and ADF $\left.-\mathrm{GLS}_{i j}^{\tau}\right)$ are the ADF test statistics performed on gap $(i, j)$ with the demeaning (detrending) carried out using ordinary least squares (OLS) and generalized least squares (GLS), respectively. The scaling factors $c_{1}, \ldots, c_{4}$ are set as in Smeekes (2011) to the negative inverse of the $\alpha$-level critical values for each test statistic, which are obtained in a preliminary bootstrap step. The UR statistic can be seen as a bootstrap version of the asymptotic test of Harvey et al. (2012) which has the advantage of allowing one to deal with uncertainty regarding both the initial condition and the deterministic trend. 
The critical values to be used at each step of the search are obtained using the block bootstrap of Smeekes (2011, Algorithm 2), which has the advantage of being able to accommodate virtually any type of serial and cross-state dependence. Suppose, therefore, that we are at step 2 of the search algorithm, and that we would like to test $H_{0}\left(q_{k}\right)$ versus $H_{1}\left(q_{k+1}\right)$. The bootstrap algorithm proceeds as follows.

\subsection{Bootstrap algorithm}

1. Regress $g_{i j, t}$ on a constant, or a constant and trend, and $g_{i j, t-1}$. By subtracting the mean from the resulting OLS residuals, we obtain the recentered residuals, $\hat{u}_{i j, t}$ say, which can be stacked into the $M$-dimensional vector $\hat{u}_{t}$.

2. Construct the bootstrap errors $u_{1}^{*}, \ldots u_{T}^{*}$ by drawing randomly from $\hat{u}_{t}$ blocks of length $b$.

3. Obtain the bootstrapped spending gaps as $\mathrm{g}_{i j, t}^{*}=\rho_{i j} \mathrm{~g}_{i j, t-1}^{*}+u_{i j, t}^{*}$, where $\mathrm{g}_{i j, 0}^{*}=0$ and $u_{i j, t}^{*}$ is the element of $u_{t}^{*}$ that corresponds to $\hat{u}_{i j, t}$. Also, $\rho_{i j}=1$ for all pairs $(i, j)$ except for those that were found to be stationary in previous steps, in which case we set $\rho_{i j}=\hat{\rho}_{i j}$, where $\hat{\rho}_{i j}$ is the estimated autoregressive slope from step 1 .

4. Obtain the bootstrapped order statistics $\theta_{(1)}^{*}, \leq \ldots \leq \theta_{(M)}^{*}$ by applying $\theta_{i j}^{*}$ to $\mathrm{g}_{i j, t}^{*}$. Set $\tau_{1}^{*}\left(q_{k}, q_{k+1}\right)=\theta_{(c k+1)}$.

5. Repeat steps $2-4 B$ times to obtain the bootstrap test statistics $\tau_{1}^{*}\left(q_{k}, q_{k+1}\right), \ldots, \tau_{\mathrm{B}}^{*}$ $\left(q_{k}, q_{k+1}\right)$. Then select the bootstrap critical value as the $\alpha$-quantile of the ordered bootstrap statistics.

\subsection{Technical issues and alternative tests}

Before we can apply BSQT, there are a number of technical choices that have to be made, including lag length, block length, and the number bootstrap replications. As is well known from the time series literature, choices of this type are very important, as different values can have a significant impact on the performance in small samples. We begin with the criterion for choosing the lag length used to account for serial correlation in the ADF test. We follow Ng and Perron (2001) and use the modified Akaike information criterion (MAIC) (with maximum lag of $\left\lfloor 12(\mathrm{~T} / 100)^{1 / 4}\right\rfloor$ ), which is an information criterion that has been tailored to particular unit root testing situation considered here. ${ }^{22}$ Next, the block length is set equal to $b=\left\lfloor 1.75 \mathrm{~T}^{1 / 3}\right\rfloor$, as in as in Palm et al. (2011). The testing is carried out at the 5\% significance level. Another important choice is the quantiles to be tested, $q_{1}, \ldots, q_{K}$. While wider quantiles leads to more information in each test, it also increases the risk that $q$, the true fraction of convergent gaps, will lie between the tested quantiles, in which case the method will be unable to detect it. For example, if the quantiles to be tested are taken as $q_{k} \in\{0,0.25,0.50,0.75\}$, the method will obviously not be able to detect if 35 or $40 \%$ of the expenditure pairs are convergent. However, since $M$ (the number of expenditure

\footnotetext{
22 Since the lag length required in the bootstrapped data need not be the same as for the original data, the MAIC is applied also within the bootstrap. For the GLS-based tests, we follow Perron and Qu (2007) and pick the lags using the OLS detrended data.
} 
gaps) is rather large in our case, the quantiles can still be made quite fine without losing too much power. Accordingly, we choose to set $q_{k} \in\{0,0.1,0.2, \ldots, 0.9\}$.

The BSQT results are compared with those obtained using the sequential panel selection method (SPSM) of Chortareas and Kapetanios (2009), which consists of carrying out a sequence of panel unit root tests, each time deleting the "most stationary" pair. The main problem with this approach, apart from the fact that it is not as general as BSQT, is that the evidence of stationarity is "smoothed out" leading to low power when compared with tests based on order statistics.

\section{Data and empirical results}

\subsection{Data}

We collected the necessary data for the 48 contiguous SLG units over the period 19572008. ${ }^{23}$ The data and definitions for nominal per capita total spending and eleven of its (sub)categories are taken from "State Government Finances" of the Census Bureau. We use the price index for "Government Consumption Expenditures and Gross Investment" at the state and local level $(2000=100)$ published by the U.S. Bureau of Economic Analysis to convert nominal values into real ones. ${ }^{24}$ The choice of state-local expenditure (sub)categories analyzed here was mainly based on data availability for the entire sample period. Brief definitions of the spending variables along with some descriptive statistics are presented in the "Data Appendix Table".

Among the expenditure categories, CAPT and CURR are "economic" categories and the rest are "functional." 25 There are some overlaps between the two types as functional categories include both current and capital expenditures. On average, CAPT accounted for roughly $15 \%$ of total spending on a real per capita basis. CAPT grew at an average annual rate of merely 0.6 which was far smaller than the $2.6 \%$ rate of growth of CURR. ${ }^{26}$ Among the functional categories, EDUC and PWEL alone accounted for over 43 percent of total real per capita spending. No other category had

\footnotetext{
23 The choice of combined state-local government units allows us to account for all within state expenditures and, at the same time, avoid complications resulting from a complex set of intergovernmental fiscal relationships between state and local governments. Note that our sample period is much longer than those of the studies reviewed earlier. This is important from the perspective of detecting convergence as a long-term phenomenon in the data.

24 Two issues regarding the data need to be pointed out. First, the Census Bureau does not report the data points for the years 2001 and 2003. We employ a simple interpolation method to replace the missing data points. Second, ideally one would like to use more refined measures of population and price index for conversion purposes to properly account for differences in the size of eligible or target population and costs of provision of specific category of goods or services across jurisdictions. Data restrictions, however, prevent this. See also footnote 6 .

25 Economic categories are defined based on economic characteristics or type of spending. Functional categories, however, are defined based on the purpose of spending.

26 In FY 2008, local governments accounted for about two-thirds of all capital spending. The main areas of capital spending at the local level were in relation to schools, general government structures, and local utilities. At the state government level, the capital spending priorities were highways and higher education (Marlowe 2012).
} 
a relative share that was greater than $10 \%$. The fastest (slowest) growing functional category was PWEL (HWAY).

\subsection{Preliminary data analysis}

For comparison purposes only, we apply two frequently used methods in previous studies to our data. The first method employs the coefficient of variation $(\mathrm{CV}=$ standard deviation/mean) to see if the cross-sectional relative) dispersion of expenditure is narrowing over time ( $\sigma$-convergence). $\mathrm{CV}$ is most informative about convergence (divergence) when it displays a fairly consistent downward (upward) trend between the beginning and end points of the sample period. Figure $1 \mathrm{a}-\mathrm{c}$ present the trends in $\mathrm{CV}$ for three groups of variables. Among the economic categories grouped together in Fig. 1a, CV-TOTL $(21.3,16.3)$ and CV-CURR $(20.4,16.1)$ show mild decline between 1957 and 2008 (sample beginning and end CV values are shown in parentheses). CV-CAPT $(29.7,33.0)$, on the other hand, does not exhibit any trend. Figure $1 \mathrm{~b}$ shows the CVs of three basic infrastructure subcategories: CV-UTIL (87.3, 73.7), CV-SANT (47.6, 28.9)

a

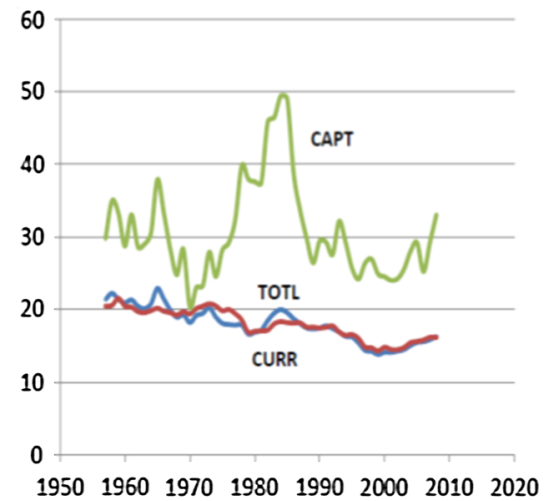

C

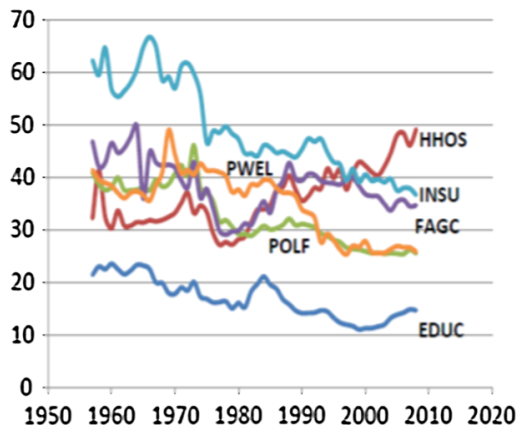

b

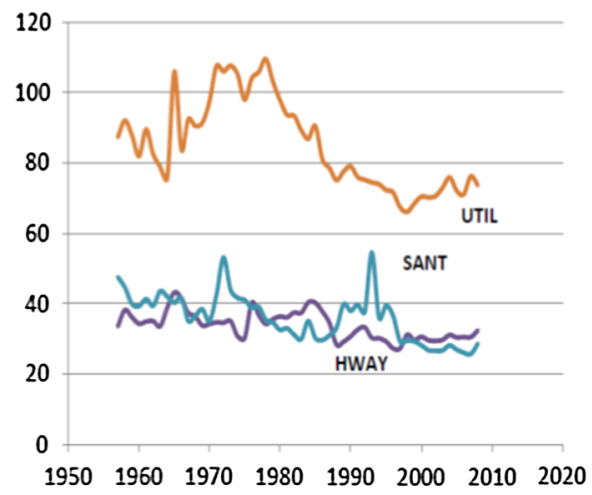

Legend:

\begin{tabular}{|c|c|}
\hline TOTL $=$ Total & POLF= Police and Fire Protection \\
\hline CURR $=$ Current & FAGC $=$ Financial Administration and General \\
\hline CAPT $=$ Capital & Control \\
\hline SANT = Sanitation & EDUC $=$ Education \\
\hline HWAY = Highway & \\
\hline UTIL = Utility & \\
\hline HHOS $=$ Health and & ospital \\
\hline PWEL = Public Wel & \\
\hline INSU = Insurance & \\
\hline
\end{tabular}

Fig. 1 Coefficient of variation of categories of state-local government real per capita expenditure (19572008, percent) 
and CV-HWAY $(33.5,32.4)$. With the exception of an extended period of decline in CVUTIL between 1978 and 1999, the subcategories do not exhibit a consistent downward trend in CV either. Finally, Fig. 1c suggests a rather steady decline in CV-INSU (62.3, 36.6), CV-PWEL (41.4, 25.9), CV-POLF (40.9, 25.5), and CV-EDUC (21.5, 14.7). Among the remaining categories, CV-HHOS $(32.2,49.1)$ exhibits a clear upward trend for much of the sample period, while CV-FAGC $(46.8,34.7)$ is essentially trendless. There are reasons for exercising caution in inferring convergence (divergence) from the dynamics of CV. To illustrate, consider the plot of the CV-CAPT series which is basically trendless over the entire sample period. However, the $\mathrm{CV}$ values may be interpreted as consistent with convergence or divergence depending on the sub-period over which they are reported. In addition, as a measure of deviations from the sample mean, CV does not reveal information about changes in bilateral gaps among units. Thus, the trendless behavior of CV-CAPT does not necessarily rule out the possibility that these gaps among (a subset of the sample) have been be narrowing over time. More generally, as the BSQT evidence presented later suggests, the link between the trend in $\mathrm{CV}$ and the fraction of convergent bilateral gaps is rather weak underscoring the interpretive issues associated with $\mathrm{CV}$.

The second method used in some previous studies is the IPS panel unit root test (Im et al. 2003). Unlike Annala and Chen (2011) who apply the IPS test to the level of spending variables, we use demeaned values to alleviate size distortion problem associated with contemporaneously correlated residuals across SLGs. We find that the null hypothesis of unit root (no convergence) can be rejected in all cases with the exception of PWEL. ${ }^{27}$ Again, interpreting this result as evidence supporting convergence (or no convergence) among all cross-sectional units may be misleading, for only a fraction of the panel in each case may be (non)stationary. With these caveats in mind, we turn to our main results based on BQST.

\subsection{Main results from sequential tests}

\subsubsection{Full panel results}

Table 1 summarizes the results of the two convergence tests in terms of the highest percent of convergent expenditure pairs (hereafter, "convergence ratio"), or more precisely, the highest percent of all pairs for which the null of a nonstationary gap could be rejected. Two general observations are in order: First, the convergence ratio varies from zero (for PWEL) to a maximum of $80 \%$ (for CAPT) with a number of values in between these two extremes. This underscores the advantage of our more nuanced approach relative to those that produced "all-or-none" type outcomes. Second, the evidence in favor of convergence is much stronger based on the BSQT when compared with the evidence produced by the SPMS test. Both tests, however, generate fairly consistent results in terms of the relative magnitudes of the convergence ratio across expenditure categories. In what follows, we focus on the results based on BQST which, for reasons noted before, is our preferred method.

27 Results are not reported here but are available from the authors upon request. 
Table 1 Percent of convergent pairwise state-local government expenditure based on alternative tests in full panel $(N=48, T=52)$

\begin{tabular}{lccccccccccccc}
\hline Test & TOTL & CURR & CAPT & SANT & HWAY & UTIL & EDUC & HHOS & PWEL & POLF & FAGC & INSU \\
\hline BSQT & 20.0 & 10.0 & 80.0 & 70.0 & 70.0 & 40.0 & 60.0 & 10.0 & 0.0 & 30.0 & 10.0 & 60.0 \\
SPSM & 12.8 & 0.0 & 39.0 & 45.4 & 40.0 & 21.4 & 32.6 & 0.0 & 0.0 & 22.0 & 2.2 & 27.3 \\
\hline
\end{tabular}

Results indicate the number of convergent pairwise spending gaps as a percent of $M=N(N-1) / 2=1128$ possible pairs

BSQT Bootstrap sequential quantile test (Smeekes 2011), SPSM The sequential panel selection method of Chortareas and Kapetanios (2009)

Expenditure variables in the top row are defined as follows: TOTL total (current plus capital), CURR current, CAPT capital, SANT sanitation, HWAY highways, UTIL utility, EDUC education, HHOS health and hospitals, $P W E L$ public welfare, FAGC financial administration and general control, INSU insurance trust benefits

Among economic expenditure categories, there is virtually no evidence of a broad spatial convergence in relation to TOTL and CURR. Based on the BSQT results, only $20 \%$ of the 1,128 possible bilateral gaps have been narrowing in the case of TOTL and merely $10 \%$ in the case of CURR. On the other hand, CAPT (with a trendless CV) shows evidence of a much broader spatial convergence at $80 \%$. Put together, these results suggest that the low convergence ratio for total expenditure largely reflects lack of convergence in the current expenditure component of it. This result is not surprising given that current expenditures comprise the bulk of total state-local expenditures.

As for basic physical infrastructure expenditures, the convergence ratio is $70 \%$ for SANT and HWAY and $40 \%$ for UTIL. These subcategories include projects that are supported by federal grants. HWAY, which has the highest spending share among the three, has particularly benefited from federal grants for a long time. Given the characteristics of federal highway grants, it is not unreasonable to conclude that they have incentivized SLG highway spending and contributed to its convergence. ${ }^{28}$

Education services (EDUC) is a category that is widely considered as a major contributing factor to enhancing the stock and quality of "human capital." Reflecting its special status, EDUC accounted for about one-third of total real per capita spending over the sample period. State governments have been traditionally responsible for higher education and local governments for elementary and secondary education. ${ }^{29}$ Against the backdrop of national emphasis on education, a drive to raise educational standards, equalizing state grants to local governments, and the importance of contiguity on spatial correlation of education spending (Coughlin et al. 2007), EDUC shows a convergence ratio of $60 \%$. Apparently, the forces driving spending convergence were strong enough to largely offset expected divergence in a category that is dominated by a very large number of local governments.

\footnotetext{
28 According to a report by the Congressional Research Service (Kirk 2013), since the early 1920s much of the federal highway funds were apportioned to the sates by formula with a matching rate of 100 percent until the 1950s. Currently, the matching rates are 80 percent for non-Interstate System road projects and $90 \%$ for Interstate System projects.

29 In 2008, about $8 \%$ of the federal grants to SLGs was allocated to education. K-12 institutions received about $55 \%$ of their funding from federal and state governments (Fisher 2010).
} 
The health and hospitals (HHOS) and public welfare (PWEL) categories comprise what is referred to as "social services and income maintenance" spending. Their combined average share of total spending on a real per capita basis was under $18.2 \%$, but they received a disproportionate share of federal grants to SLGs. The convergence evidence for HHOS is quite weak (10\% at best). This result is consistent with the weak evidence of convergence for this category found by a number of previous studies. Coughlin et al. (2007, p. 377) explain their result by noting that "Health expenditures are likely to be based on the health needs of each state's population. It is more difficult for a state to change its health expenditures when its population and its health needs are relatively constant one year to the next. States may thus find it more difficult to spend more on health than is needed by its population." PWEL, dominated by Medicaid, enjoyed the fastest rate of growth $(3.7 \%)$ among all the functional categories ${ }^{30}$ Over $50 \%$ of all federal grants went to Medicaid alone mainly in the form of payments to vendors and private health care providers. Given these, the finding of a zero convergence ratio for PWEL (with a mostly downward trending CV) is a rather surprising result.

A question that arises is why spending on the Medicaid has apparently failed to converge despite of being heavily subsidized by the federal government? ${ }^{31}$ A report prepared for the Department of Health and Human Services (The Lewin Group 2004) offers some possible explanations. According to the report, over the period 1977-2003, there has been a major shift in the composition of social welfare budgets in states of all fiscal capacity towards Medicaid spending. Although federal grants constituted a larger share of a much lower own-source spending on Medicaid in poor states, they did not narrow absolute Medicaid spending gaps between poor and rich states. This was because rich states spent more out of their own-source revenues and thus received grants whose average dollar amount was actually higher than those received by poor states. ${ }^{32}$

Another part of the answer may lie in the cross-state variations in Medicaid benefit packages. States enjoy significant discretion and flexibility in administering their own (expanded) programs by establishing eligibility standards and determining the amount, duration, scope, and provider payments in relation to Medicaid services they fund within federal guidelines (including "core requirements") and in the form of "optional benefits." (See, for example, Snyder et al. 2012; Center on Budget and Public Policy 2013). One may argue that diversity in Medicaid's program design, reflecting heterogeneity in preferences and fiscal and political institutions, (more) than offset the

\footnotetext{
30 PWEL has a health related component (Medicaid), a non-health social services component (such as childcare and child welfare), and a "cash assistance" component (such as Aid to Families with Dependent Children, or AFDC, and its replacement Temporary Assistance for Needy Families, or TANF).

31 States receive an (open-end) categorical grant with a matching rate for their Medicaid expenditures. The rate, referred to as the Federal Medical Assistance Percentage (FMAP), varies across states depending on criteria such as per capita income. The regular FMAP has a range of 50-82\% (with an average rate of $57 \%$ ). States also receive matching funds for "optional benefits" they choose to provide. See Medicade.gov for the full FMAP table.

32 Baicker et al. (2012, p. 1089) note that an increase in the federal minimum eligibility floor allows richer states already above the floor to further increase their spending as the floor increase relaxes constraints associated with interstate fiscal competition.
} 
equalizing effects of grants and prevented convergence in PWEL. Lastly, SLGs vary in terms of demographic factors, such as the age composition of population and the percent of women of childbearing age and African American, which significantly affect the demand for health care services provided by Medicaid (Cuckler et al. 2011).

"Public safety" spending (POLF) is a spending category with a period average share of $4.1 \%$ and a significant local component. Its size is almost entirely determined by local government decisions based on local community needs and resources. Given the large number of local jurisdictions in the USA (over 80,000), the demand of public safety service is highly varied both across states and localities within a state. Accordingly, the relatively low (30\%) convergence ratio for this category is not surprising. FAGC or governmental administration (with period average share of $3.8 \%$ ) is essentially a non-convergent category also due to varied standards and needs of localities.

Another surprising result is the $60 \%$ convergent ratio for the "insurance trust and benefits" (INSU) component of (the non-convergent) current expenditures. INSU had the second highest growth rate $(3.1 \%)$. The bulk of INSU spending went to "employee retirement." Thus, the driving force for convergence should be sought mainly in this component of INSU. A number of studies have suggested that SLG employee pension plans are significantly underfunded in the sense that the present value of future benefits promised (liabilities) exceeds the plans' assets set aside to fund them. ${ }^{33}$ In this context, pension fund managers use contributions of current employees to pay benefits to current retirees (Rauh 2010). Accordingly, lack of a hard budget constraint might have contributed to growth of benefits especially where they were initially low. Other possible explanations are the effects on retirement benefits of public employee unions, rising life expectancy, and the growth of SLG employment to the extent that these effects were larger in poor- low-spending states. ${ }^{34}$

\subsubsection{Club convergence results}

We next examine whether convergence is a "club" phenomenon using geographic proximity to capture similarities among member states. To this end, we calculate the convergence ratio within several regional subsamples. Regions provide a broad context for geographic spillovers, for they include a group of states not all of which are geographically contiguous but share other characteristics. Our regional classifications are from the Bureau of Economic Analysis (BEA). ${ }^{35}$

\footnotetext{
33 See, for example, Public Fund Survey (2013) available at http://www.publicfundsurvey.org. Accumulation of future liabilities is masked by governments" use of a "cash-flow" based accounting method in which revenues (expenditures) are recorded when they are received (paid) instead of an "accrual" based accounting method which records revenues (expenditures) when the rights to receive (obligations to pay) arise (Block 2008).

34 Our simple calculations, based on the Census Bureau state employment data (available at http://www. governing.com), indicate that Mississippi and Massachusetts, for example, experienced an average annual state employment of 6.4 and $2.5 \%$ between 1960 and 2008, respectively. Over the same period, the real per capita INSU spending grew at an average annual rate of 4.0 and 2.2\% in Mississippi and Massachusetts, respectively.

35 The BEA's guiding principle for grouping states into regions is homogeneity with respect to economic and social factors. The following classifications are used: New England (Connecticut, Maine, Massachusetts,
} 
In our context, club convergence is measured in terms the proportion of a region's total convergent expenditure pairs that is intraregional ("intraregional convergence ratio," hereafter). ${ }^{36}$ To obtain this proportion, we first determine the number of total convergent pairs for each of the 48 SLG units (see the next subsection). Using the individual unit results, we next calculate for each region the number of all intraregional convergent pairs as a percent of the region's total number convergent pairs.

Table 2 shows the intraregional convergent ratios. To put the percent values in perspective, the corresponding number of total convergent pairs is also reported underneath each percent value. ${ }^{37}$ Caution must be exercised in interpreting the results. While a high percent in any individual case indicates a high proportion of intraregional convergent pairs, the percent values are not strictly comparable across rows and columns in view of variations in the number total of pairs. It is immediately apparent from Table 2 that there is little support for intraregional convergence as the majority of reported values are less than 15 percent. So to the extent that convergence is actually occurring much of it is of interregional type. One possible explanation for these results is the diminished importance of geographic proximity over time as lower transportation and communication costs have increased cross-regional mobility.

The closest we come to a "club convergence" outcome is in relation to the Southeast region which has a relatively high percent of intraregional convergent gaps in a number spending categories. Apparently, interstate spending spillovers are relatively more significant in this region whose states are bonded together by their historical heritage and are similar with respect to characteristics such as relatively conservative political and fiscal institutions as well as high proportion of poor population and degree of reliance on federal grants.

\subsubsection{Individual state-local government results}

Having discussed the results at high and intermediate levels of aggregation, we now turn to individual SLG results. The objective here is to determine which SLG unit has been most convergent and in what spending category. For each unit, we calculate its convergence ratio as the total number its convergent expenditure pairs divided by $47(=N-1) .{ }^{38}$ The ratio may be loosely interpreted as the extent to which a SLG

\section{Footnote 35 continued}

New Hampshire, Rhode Island, and Vermont); Mideast (Delaware, Maryland, New Jersey, New York, and Pennsylvania); Great Lakes (Illinois, Indiana, Michigan, Ohio, and Wisconsin); Plains (Iowa, Kansas, Minnesota, Missouri, Nebraska, North Dakota, and South Dakota); Southeast (Alabama, Arkansas, Florida, Georgia, Kentucky, Louisiana, Mississippi, North Carolina, South Carolina, Tennessee, Virginia, and West Virginia); Southwest (Arizona, New Mexico, Oklahoma, and Texas); Rocky Mountain (Colorado, Idaho, Montana, and Utah); and Far West (California, Nevada, Oregon, and Washington). Note that we excluded both Alaska and Hawaii from the Far West region as fiscal outliers.

36 For a region with $\mathrm{n}$ states, there are $n(n-1) / 2$ intraregional gaps and $n(N-n) / 2$ interregional gaps where $N=48$.

37 For example, the $15.8 \%$ shown for New England under TOTL means that out of a total 38 convergent total expenditure pairs found for the region's member states six were intraregional.

38 Note that in determining the numerator of this ratio, the case of a convergent spending pairs between units $\mathrm{X}$ and $\mathrm{Y}$, unlike in Tables 1 and 2, is counted separately for each unit. Also, as in Table 1, the denominator is a fixed number which means that a higher ratio necessarily means a higher number of convergent pairs. 


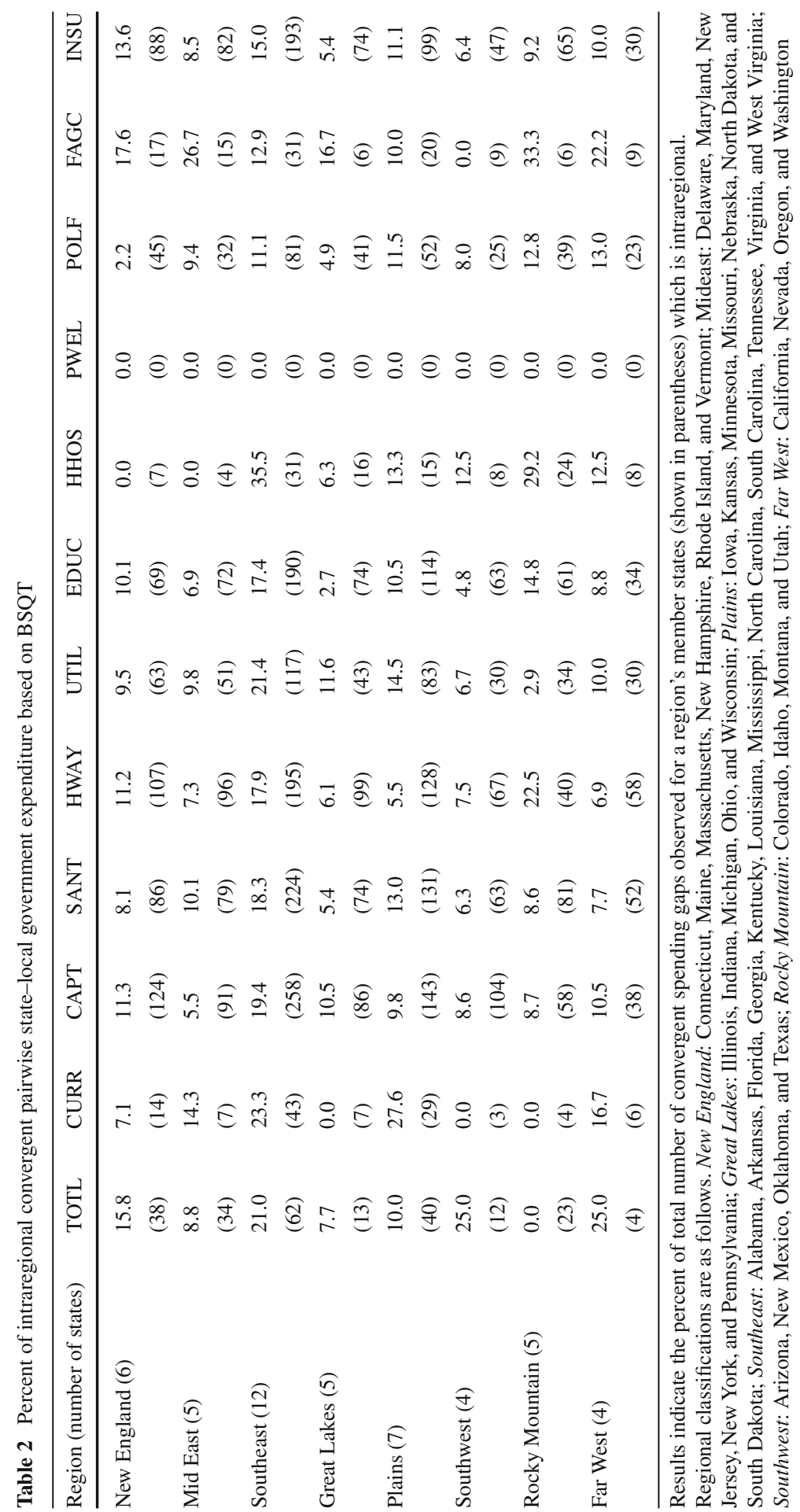


unit's spending is "linked" to those of other units. Table 3 shows the results in percent terms with the top (bottom) $5 \%$ values in each column shown in bold (italic) type. ${ }^{39}$ To facilitate comparisons, results are presented based on regional classifications along with regional ratio averages. In the last column, the average values of the convergence ratios for each unit's functional categories are also shown. These values provide a broad picture of spending linkage for each unit. The results indicate wide diversity in convergence patterns both across SLGs and spending categories. Given this, our discussion of the results is necessarily selective.

The convergence ratio for TOTL ranges from $0 \%$ (WY) to 53.2 percent (DE). Accordingly, $25(=0.532 \times 47)$ states narrowed their real per capita spending gaps with DE, but none with WY. If we decompose TOTL into its constituent components (CURR and CAPT), it becomes clear that low (high) convergence ratio of TOTL in each state is mainly a reflection of the low (high) convergence ration of CURR. The convergence ratio range for CURR is 0 (NY) to 89.4 (ND) \%, but ND is a clear outlier and the next highest value is $23 \%$ (RI). CAPT has a range of 17.0 (CA) to 97.9 (WA) \%. As for the nine functional categories, we first examine the average values for each state shown in the last column. The highest value observed is $51.1 \%$ for DE. The large and influential state of CA stands out for having the lowest average value $(22.7 \%)$ in the sample.

Regional overall convergence ratio averages in the last column suggest that Mid East is the most convergent region and Far West the least. The Plains and Rocky Mountain regions have the highest average convergence ratios in relation CAPT or infrastructure subcategories. The Mid East states have the highest convergence ratios in the categories of EDUC and INSU.

Several patterns in individual state results merit further discussion. Firstly, MS, LA, AR, AL, and NM are low-income and high-grant receiving states that rank high in terms of their "expenditure need" and low according to their "expenditure effort" index values. ${ }^{40}$ In view of this, the fact that all these states show evidence of narrowing expenditure gaps is a positive development. In particular, note that MS has the highest functional category average value $(49.4 \%)$ and the other four states have average values in the low to mid $40 \%$ range. Secondly, among the rich and high-spending states, $\mathrm{CA}$ is unique in that is has relatively low convergence ratios across all the spending categories including CAPT. This suggests that CA has been on a spending path that has been largely independent of the paths of other states. It is worth noting that, compared with other high-income and high-spending states (such as CT, MA, and CT), CA ranks higher in terms of its "expenditure need," but lower in terms of its "expenditure effort" index values. Lack of convergence for CA, therefore, is not due to the state's actual expenditure being much higher than what it "needs" to spend. Thirdly, the case of the Dakotas (ND and SD) is instructive as it illustrates why broad generalizations in convergence analyses should be avoided. The two states distinguish themselves as neighbors with many common factors and high convergent ratios. Both states are

\footnotetext{
39 For example, the $31.9 \%$ reported for AL under TOTL implies that AL's total spending had convergent pairs with 15 other states from the same region as AL, or other regions.

40 Yilmaz et al. (2006, p. vi) define expenditure need as "the amount that a state would have to spend on its residents to provide services on par with the national average." A high (low) expenditure effort indicates that the state is actually spending more (less) than its expenditure need.
} 


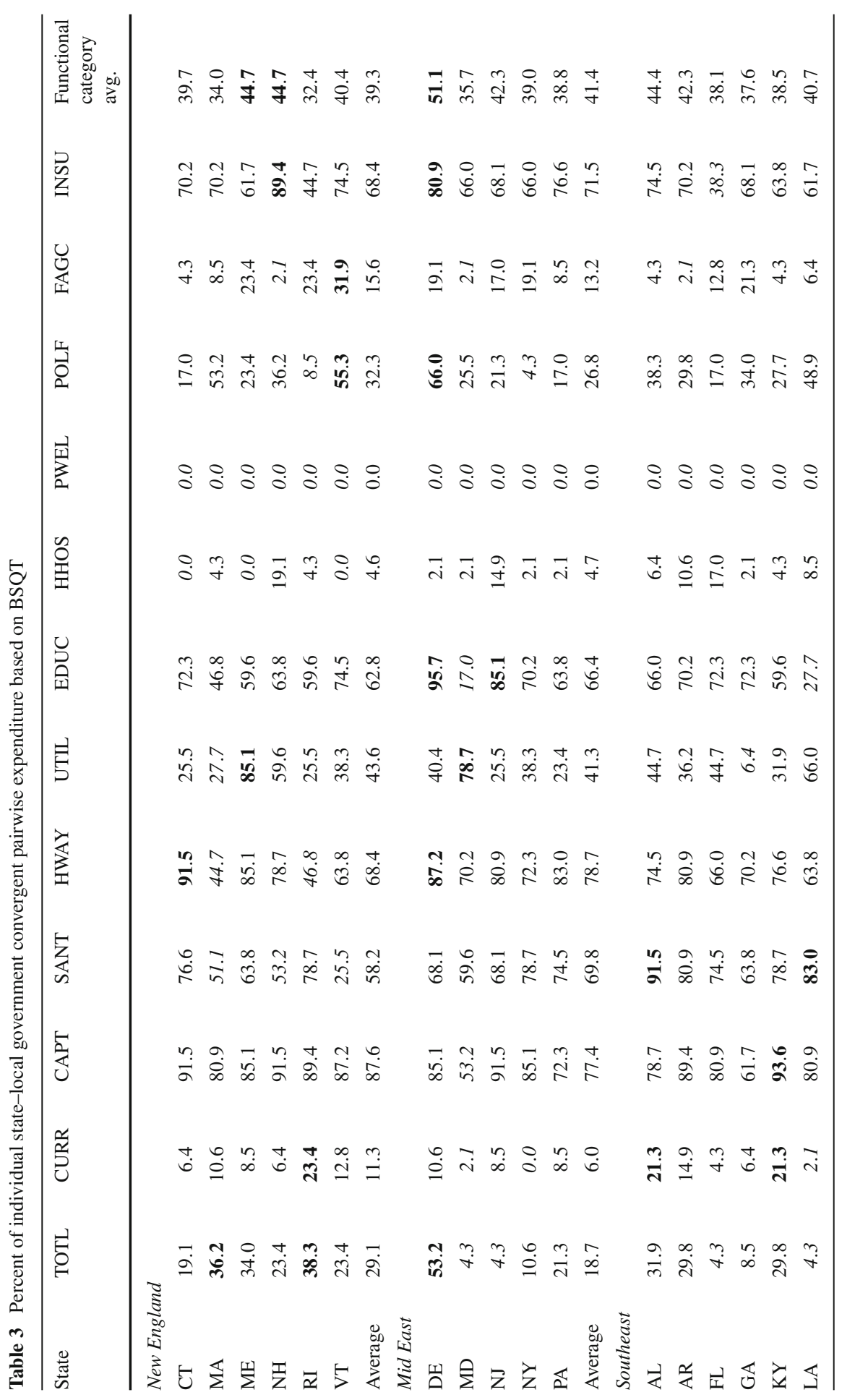




\begin{tabular}{|c|c|c|c|}
\hline 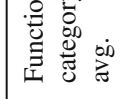 & 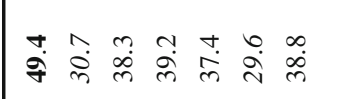 & 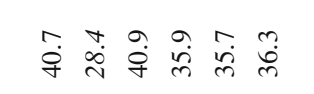 & 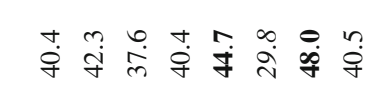 \\
\hline$\overline{\tilde{z}}$ & 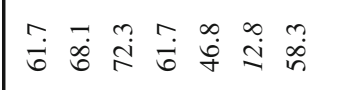 & 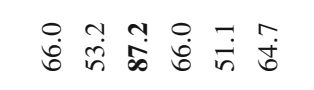 & 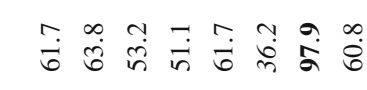 \\
\hline 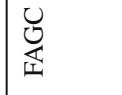 & 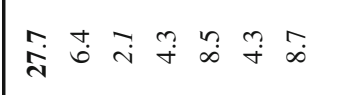 & 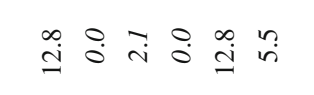 & 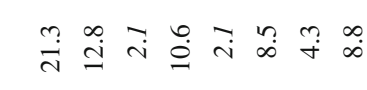 \\
\hline 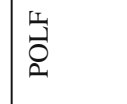 & 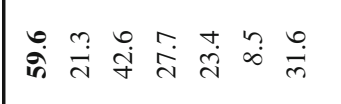 & 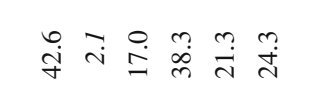 & 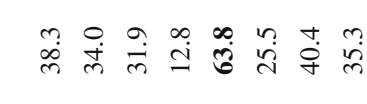 \\
\hline$\sum_{2}^{\frac{N}{2}}$ & $: \&: \&: 8: 8$ & $:: \circ:: \circ:$ & $:: 8: 8: 8: 8$ \\
\hline 垔 & 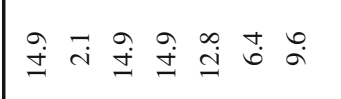 & 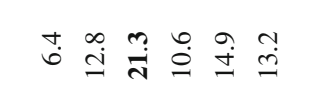 & 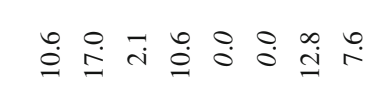 \\
\hline 党 & 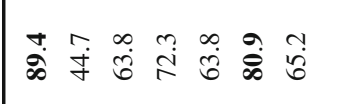 & 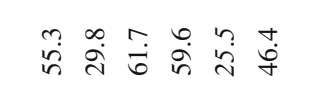 & 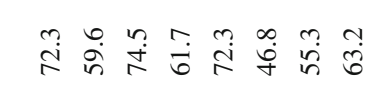 \\
\hline 咅 & 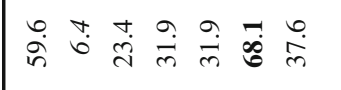 & 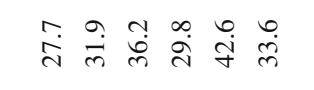 & 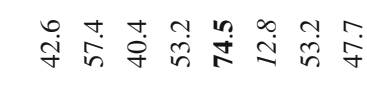 \\
\hline 3 & 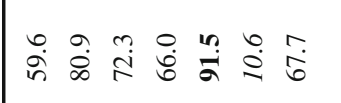 & 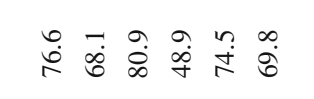 & 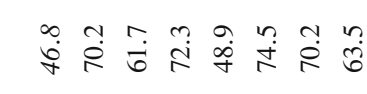 \\
\hline$\sum_{x}$ & 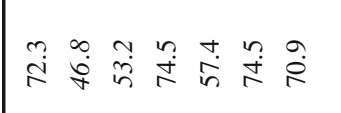 & 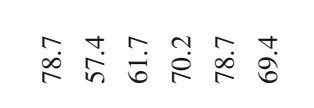 & 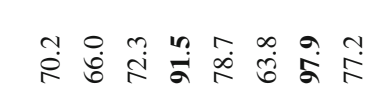 \\
\hline$\stackrel{\hat{z}}{\mathrm{z}}$ & 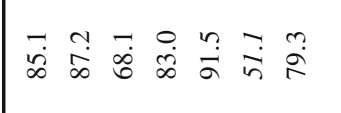 & 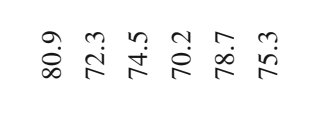 & 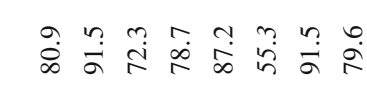 \\
\hline 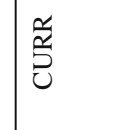 & 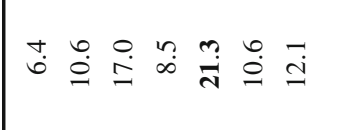 & 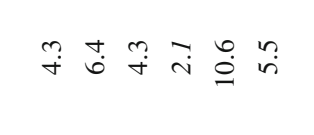 & 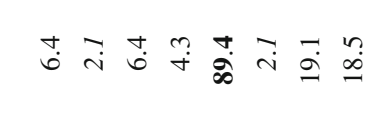 \\
\hline$\exists$ & 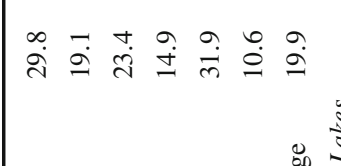 & 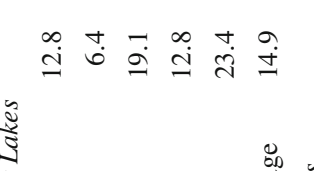 & 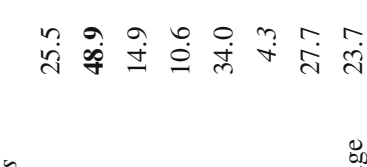 \\
\hline
\end{tabular}




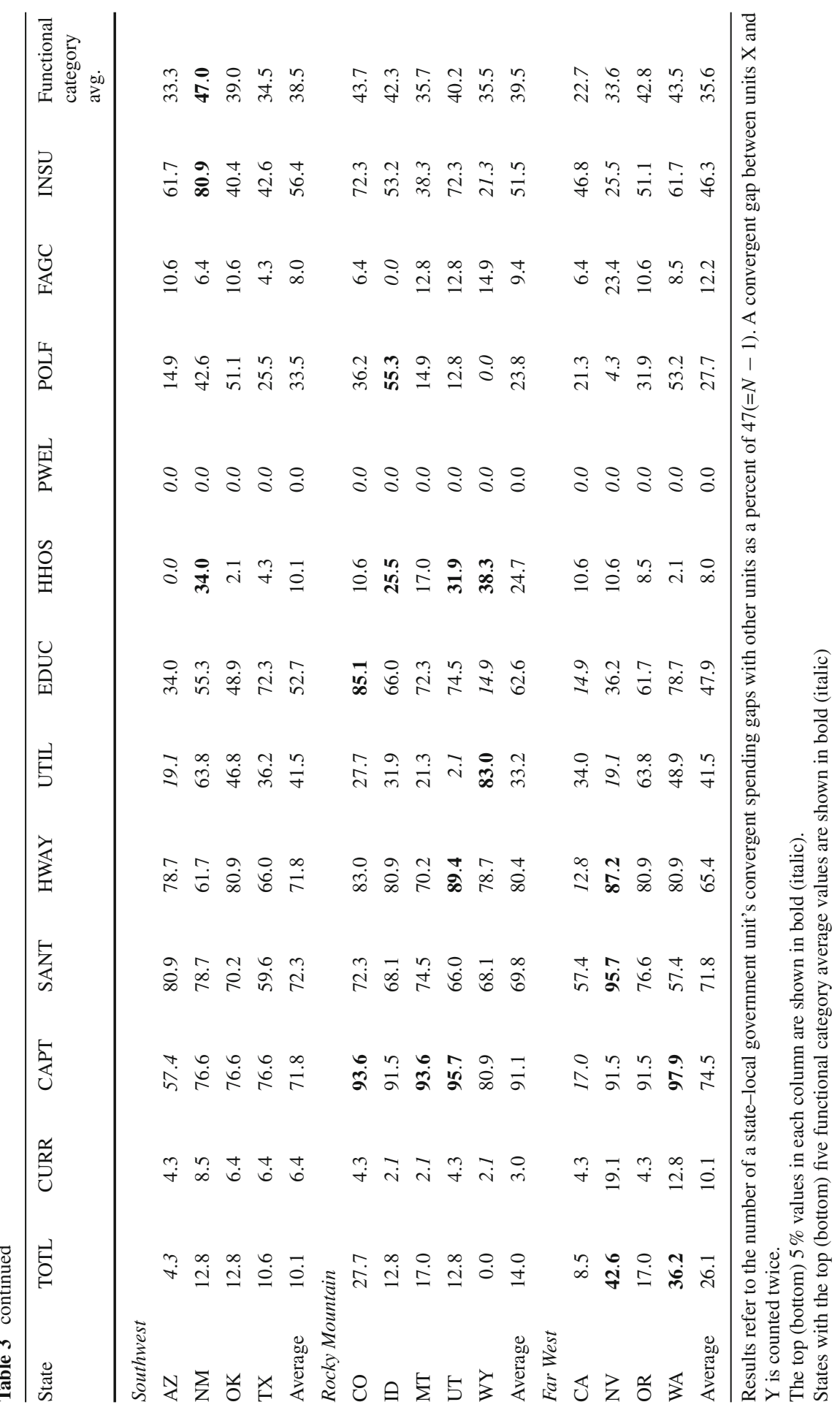


ramping up their spending as a result of an economic boom associated with energy (ND) and banking and finance (SD). Yet, these two states have different patterns of convergent gaps. ND seems to be narrowing both its CURR and CAPT spending gaps with the majority of other states. On the other hand, SD, which is the poorer of the two states, seems to have been emphasizing the narrowing of its CAPT spending gaps.

Finally, there is some tentative evidence that fiscal institutions in the form of Tax and Expenditure Limits (TELs) affect spending convergence. ${ }^{41}$ Using ordinal rankings of state TELs stringency scores assigned by Resnick (2002) based on several criteria, we find that states with the most stringent TELs (CO, MO, LA, CA, WA, AZ, and OK) had an average current expenditure convergence ratio of $5.5 \%$. The corresponding ratios for states with moderate (CT, DE, FL, SC, TN, TX, NV, and OR) and low (MA, RI, NC, UT, NJ, MS, IA, MT, ID, AR, and SD) stringency scores were 9.6 and $5.8 \%$, respectively. States with no TELs, on the other hand, had a nearly $20 \%$ convergence ratio. However, this evidence is merely suggestive and inferring a causal link between TELs and the convergence ratio requires a more formal analysis that is beyond the scope of this paper.

\section{Concluding remarks}

Are state and local government expenditures converging? We employed a novel methodology which enabled us to estimate the proportion of convergent expenditure pairs to provide a more nuanced answer to this question. Our results suggested that convergence was a "matter of degree." This calls into question the findings of previous studies which implied that convergence (or lack of it) was a panel-wide phenomenon. Moreover, the convergence ratio significantly varied across expenditure categories. In relation to broadly defined economic categories, the convergence ratio for capital outlays was eight times that of current expenditures (80 vs. 10\%) based on our preferred testing method. Thus, the bulk of total state-local government expenditures was non-convergent. Among functional categories, basic infrastructure, education, and insurance trust benefits showed stronger evidence of convergence than health and hospitals, police and fire protection, governmental administration, and public welfare.

We found little support for existence of regional convergence clubs based on the notion that geographic proximity and common characteristics among states belonging to the same region would be associated with a higher proportion of the region's all convergent pairs being of intraregional type. Our results further indicated that Delaware was the most convergent and California the least convergent of all states based on the average convergence ratio of the functional categories. Between these two extremes, there were a wide variety convergence patterns. Several low-income and high-grant receiving states were noteworthy for their relatively high convergence ratios in several categories.

The strong convergence evidence in relation to capital outlays may reflect several factors: (a) voters receive tangible benefits from spending on immobile infrastructure,

41 Beginning 1978, TELs were instituted in a number of states with the objective of reigning the state budget by slowing down the rates of growth of taxes and expenditures. 
(b) the benefits associated with additional spending are higher where infrastructure investment deficiencies exist, and (c) as argued by Milesi-Ferretti et al. (2002), elected officials under a majoritarian electoral system pay more attention to infrastructure spending which is more easily targeted to their geographic constituencies than redistributive transfers. This is particularly the case when capital projects are presented as a critical factor for increasing a state's ability to compete with other states for trade and investments and, ultimately, raising its economic growth. The favorable attitude on the side of both the electorate and elected officials softens up political resistance to spending on capital projects even in fairly politically conservative states (Colorado, Montana, and Utah, North Dakota, and South Dakota, for example, which rank high in terms of their capital outlay convergence ratio). The essence of this argument may also apply to spending on education a significant portion of which is on physical capital. Also, education often enjoys wide popular support and special status as the building block for economic competitiveness and prosperity. In sum, "keeping up with the Joneses" is relatively easier to justify in relation to "productive" expenditures. Other spending categories, however, are relatively less favorably looked upon by members of the public and elected officials especially in conservative states and localities. Social welfare is particularly politically contentious in part due to ideological reasons. More practical considerations, such as the fear of becoming a "welfare magnet," while apparently not triggering off a "race to the bottom," can impose enough constraints on welfare spending to prevent its convergence around an upward spending trend.

Our findings have several implications. (a) To the extent that public expenditures on infrastructure and education are growth augmenting, their spatial convergence should help drive future spatial convergence in output. (b) The role of state-local government infrastructure and education spending in business location choices should diminish as spending on these categories converge over time. (c) The low convergence ratios associated with health and hospitals, police and fire protection, governmental administration, and public welfare spending reflect differences in local preferences, standards, and needs. Since localities apparently are sufficiently differentiated with respect to these services and benefits that influence one's choice of residence, the prospect for Tiebout-type migration cannot be ruled out. (d) Federal grants have been singled out by Baicker et al. (2012) as instrumental in increasing the size of state and local government budgets. The evidence presented in this paper, however, suggests that the role of federal grants in inducing spatial expenditure convergence, especially in relation to non-capital outlays, is much less clear-cut. Lack of convergence in public welfare spending, where preference and institutional heterogeneity play a more pronounced role, suggests that grants can increase the size of spending in some areas without inducing spending convergence. On the other hand, the narrowing of non-welfare spending gaps especially in a number of low-income states suggests that the leveling effects of federal grants are hard to ignore.

Open Access This article is distributed under the terms of the Creative Commons Attribution 4.0 International License (http://creativecommons.org/licenses/by/4.0/), which permits unrestricted use, distribution, and reproduction in any medium, provided you give appropriate credit to the original author(s) and the source, provide a link to the Creative Commons license, and indicate if changes were made. 


\section{Appendix}

See Table 4.

Table 4 Data appendix table. Per capita real expenditure (1957-2008). Source: Authors' calculations

\begin{tabular}{|c|c|c|c|c|}
\hline $\begin{array}{l}\text { Expenditure } \\
\text { variable }\end{array}$ & Expenditure (sub)category definition & Mean & Growth rate & $\begin{array}{l}\text { Share of } \\
\text { total }\end{array}$ \\
\hline TOTL & Total (equals current plus capital) & $\$ 6127$ & 2.2 & 100.0 \\
\hline CURR & $\begin{array}{l}\text { Current: current operations, assistance and } \\
\text { subsidies, interest on debt, and insurance } \\
\text { benefits and Payments }\end{array}$ & 5189 & 2.6 & 84.7 \\
\hline CAPT & $\begin{array}{l}\text { Capital: all direct expenditures on contract or } \\
\text { force account construction of structures } \\
\text { buildings, grounds, and other improvements, } \\
\text { and purchase of equipment, land, and } \\
\text { structures }\end{array}$ & 938 & 0.6 & 15.3 \\
\hline SANT & $\begin{array}{l}\text { Sanitation: sewerage and solid waste } \\
\text { management }\end{array}$ & 155 & 2.2 & 2.5 \\
\hline HWAY & $\begin{array}{l}\text { Highways: construction, maintenance, and } \\
\text { operation of highways, streets, and related } \\
\text { structures }\end{array}$ & 574 & 0.0 & 9.4 \\
\hline UTIL & $\begin{array}{l}\text { Utility: construction of utility facilities or } \\
\text { equipment, for production and distribution of } \\
\text { utility commodities and services }\end{array}$ & 381 & 1.9 & 6.2 \\
\hline EDUC & $\begin{array}{l}\text { Education: schools, colleges, and other } \\
\text { educational institutions }\end{array}$ & 1957 & 2.2 & 31.9 \\
\hline HHOS & $\begin{array}{l}\text { Health and hospital: outpatient health services, } \\
\text { other than hospital care, as well as financing } \\
\text { construction acquisition, maintenance or } \\
\text { operation of hospital facilities, provision of } \\
\text { hospital care, and support of public or private } \\
\text { hospitals (includes cash assistance and direct } \\
\text { payments to vendors for medical care } \\
\text { (Medicaid), but excludes }\end{array}$ & 419 & 2.4 & 6.8 \\
\hline PWEL & $\begin{array}{l}\text { Public welfare: support of and assistance to } \\
\text { needy persons contingent upon their need } \\
\text { pensions to former employees and other } \\
\text { benefits not contingent on need) }\end{array}$ & 700 & 3.7 & 11.4 \\
\hline INSU & $\begin{array}{l}\text { Insurance trust: cash payments to beneficiaries } \\
\text { (including withdrawals of retirement } \\
\text { contributions) of employee retirement, } \\
\text { unemployment compensation, workers' } \\
\text { compensation, and disability benefit social } \\
\text { insurance programs }\end{array}$ & 400 & 3.3 & 3.5 \\
\hline POLF & $\begin{array}{l}\text { Police and fire protection: preservation of law } \\
\text { and order and traffic safety as well as } \\
\text { fire-fighting organization and auxiliary } \\
\text { services }\end{array}$ & 251 & 2.4 & 4.1 \\
\hline
\end{tabular}


Table 4 continued

\begin{tabular}{llccc}
\hline $\begin{array}{l}\text { Expenditure } \\
\text { variable }\end{array}$ & Expenditure (sub)category definition & Mean & Growth rate & $\begin{array}{c}\text { Share of } \\
\text { total }\end{array}$ \\
\hline FAGC & $\begin{array}{l}\text { Financial administration and general control: the } \\
\text { functions of financial administration, judicial } \\
\text { and legal, and general public buildings }\end{array}$ & 234 & 2.4 & 3.8 \\
\hline
\end{tabular}

More detailed expenditure e(sub)category definitions are available at Census Bureau: http://www.census. gov/govs/definitions/

\section{References}

Advisory Commission on Intergovernmental Relations (ACIR) (1991) Interjurisdictional tax and policy competition: good or bad for the federal system? M-177, Washington, DC

Annala CN (2003) Have state and local fiscal policies become more alike? Evidence of beta convergence. Public Finance Rev 31(2):144-165

Annala C, Chen S (2011) Convergence of state and local fiscal policies: an application of panel unit root tests. J Econ Econ Educ Res 12(1):27-40

Baicker K (2005) The spillover effects of state spending. J Public Econ 89(2-3):529-544

Baicker K, Clemens J, Singhal M (2012) The rise of the states: U.S. fiscal decentralization in the postwar period. J Public Econ 96(11-12):1079-1091

Bailey MA, Carl R (2004) A wider race? Interstate competition across health and welfare programs. J Polit 66(2):326-347

Barro R (1990) Government spending in a simple model of endogenous growth. J Polit Econ 98(5):103-125

Besley T, Case A (1995) Incumbent behavior: vote-seeking, tax-setting, and yardstick competition. Am Econ Rev 85(1):25-45

Block C (2008) Budget gimmicks. In: Graddy EA, Jackson HE, Garrett E (eds) Fiscal challenges, an interdisciplinary approach to budget policy. Cambridge University Press, Cambridge, pp 39-67

Brooks L, Phillips JH (2010) An institutional explanation for the stickiness of federal grants. J Law Econ Organ 24:243-264

Case A, Hines J, Rosen H (1993) Budget spillovers and fiscal policy interdependence. J Public Econ 52:285-307

Center on Budget and Public Policy (CBPP) (2013) Policy basics: introduction to medicaid. http://www. cbpp.org/cms/index.cfm?fa=view\&id=2223

Chernick H (2000) Federal grants and social welfare spending: do state responses matter? Natl Tax J 53(1):143-152

Chortareas G, Kapetanios G (2009) Getting PPP right: identifying mean-reverting real exchange rates in panels. J Bank Finance 33(2):390-404

Congressional Budget Office (CBO) (2013) Federal grants to state and local governments. CBO, Washington, DC

Coughlin CC, Garrett TA, Hernández-Murillo R (2007) Spatial dependence in models of state fiscal policy convergence. Public Finance Rev 35(3):361-384

Cuckler G, Martin A, Whittle L, Heffler S, Sisko A, Lassman D, Benson J (2011) Health spending by state of residence, 1991-2009. Med Med Res Rev 1(4):1-31

Cyrenne P, Manish P (2015) Fiscal equalization, government expenditures and endogenous growth. Int Tax Public Finance 22(2):311-329

Dahlby B, Ferede E (2014) The stimulative effects of intergovernmental grants and the marginal cost of public funds. In: CESifo conference in public economics, Munich (Germany)

Fisher RC (1982) Income and grant effects on local expenditure: the flypaper effect and other difficulties. J Urban Econ 12(3):324-345

Fisher RC (2010) The state of state and local government. Finance Fed Reserve Bank St. Louis Reg Econ Dev 6(1):4-22

Fisher RC, Navin JC (1992) State-local fiscal behavior: analysis of interjurisdictional differences, $1962-$ 1987. Public Finance Rev 20(4):433-449 
Gramlich EM, Harvey G (1973) State and local fiscal behavior and federal grant policy. Brook Papers Econ Act 1:15-58

Harvey DI, Leybourne SJ, Taylor AMR (2012) Testing for unit roots in the presence of uncertainty over both the trend and initial condition. J Econom 169(2):188-195

Hines J, Thaler R (1995) The flypaper effect. J Econ Perspect 9:217-226

Holcombe R, Stroup M (1996) The role of federal funding on the demand for state and local government spending. Atl Econ J 24(2):131-143

Im KS, Pesaran MH, Shin Y (2003) Testing for unit roots in heterogeneous panels. J Econom 115(1):53-74

Islam N (2008) What have we learned from the convergence debate? J Econ Surv 17(3):309-354

Kenworthy L (1999) Economic integration and convergence: a look at the U.S. states. Soc Sci Q 80(4):858869

Kenyon DA (1997) Theories of interjurisdictional competition. N Engl Econ Rev 1(March/April):13-35

Kirk R (2013) Federal-aid highway program (FAHP): In: Brief, Congressional Research Service, R42793, Washington DC

Mahdavi S (2011) A re-examination of Wagner's law based on disaggregated U.S. state-local government expenditure. J Econ Stud 38(4):398-413

Maria M-FG, Roberto P, Massimo R (2002) Electoral systems and public spending. Q J Econ 117(2):609_ 657

Marlowe J (2012) Capital budgeting and spending. In: Ebel D, Petersen JE (eds) The Oxford handbook of state and local government finance. Oxford University Press, New York, pp 658-681

McKenzie Richard B, Staff Robert B (1978) Revenue sharing and monopoly government. Public Choice 33:93-97

Musgrave RA (1969) Fiscal systems. Yale University Press, New Haven

Nathan RP (1996) The 'devolution revolution': an overview. In: Nelson A (eds) Rockefeller Institute of Government. Rockefeller Institute Bulletin, Albany, pp 5-13

$\mathrm{Ng} \mathrm{S}$, Perron P (2001) Lag length selection and the construction of unit root tests with good size and power. Econometrica 69(6):1519-1554

Oates W (1999) An essay on fiscal federalism. J Econ Lit 37(3):1120-1149

Oates W, Schwab Robert M (1988) Economic competition among jurisdictions: efficiency enhancing or distortion inducing? J Public Econ 35(3):333-354

Palm FC, Stephan S, Jean-Pierre U (2011) Cross-sectional dependence robust block bootstrap panel unit root tests. J Econom 163(1):85-104

Peacock A (2006) Wagner's law of increasing expansion of public activities. In: Ott AF, Cebula RJ (eds) The Elgar companion to public economics. Edward Elgar, Aldershot, pp 25-29

Peacock A, Scott A (2000) The curious attraction of Wagner's Law. Public Choice 102:1-17

Perron P, Qu Z (2007) A simple modification to improve the finite sample properties of Ng and Perron's unit root tests. Econ Lett 94(1):12-19

Pesaran MH (2007) A pair-wise approach to testing for output and growth convergence. J Econom 138:312355

Public Fund Survey (2013) Summary of findings FY 2012. National Association of State Retirement Administrators and National Council on Teacher Retirement

Quah DT (1996) Empirics for economic growth and convergence. Eur Econ Rev 40:1353-1375

Rauh JD (2010) Are state public pensions sustainable? Why the federal government should worry about state pension liabilities. Natl Tax J 63(3):585-602

Resnick P (2002) Fiscal cap style TELs in the states: an inventory and evaluation. CPEC Center for Tax Policy. http://centerfortaxpolicy.org/reports/fiscal_cap.pdf

Robin B, Jean-François T (2012) Reassessment of the Tiebout model. J Public Econ 96(11):1063-1078

Romer PM (1986) Increasing returns and long-run growth. J Polit Econ 94(5):1002-1037

Scully GW (1991) The convergence of fiscal regimes and the decline of the Tiebout effect. Public Choice 72(1):51-94

Shannon J (1989) Competition: federalism's ‘invisible' regulator. Intergovermental Perspective (Winter). U.S. Advisory Commission on Intergovernmental Relations, Washington, DC, pp 28-30

Skidmore M, Toya H, Merriman D (2004) Convergence in government spending: theory and cross-country evidence. Kyklos 57(4):587-619

Skidmore M, Deller S (2008) Is local government spending converging? East Econ J 34(1):41-55 
Smeekes S (2011) Bootstrap sequential tests to determine the stationary units in a panel. Research Memorandum 003. Maastricht University, Maastricht Research School of Economics of Technology and Organization (METEOR)

Snyder L, Rudowitz R, Garfield R, Gordon T (2012) Why does medicaid spending vary across states: a chart book of factors driving state spending. The Kaiser Commission on Medicaid and the Uninsured. http://kaiserfamilyfoundation.files.wordpress.com/2013/01/8378.pdf

Solow R (1956) A contribution to the theory of economic growth. Q J Econ 70:65-94

Stephan S, Robert TAM (2012) Bootstrap union tests for unit roots in the presence of nonstationary volatility. Econom Theory 28(2):422-456

Tannenwald R (1998) Implications of the Balanced Budget Act of 1997 for the "devolution evolution". Publius J Fed 28(1):23-48

The Lewin Group (2004) Spending on social welfare programs in rich and poor states. Report prepared for Department of Health and Human Services Assistant Secretary for Planning and Evaluation

Tiebout C (1956) A pure theory of local expenditures. J Polit Econ 64(5):416-424

Volden G (1999) Asymmetric effects of intergovernmental grants: analysis and implications for U.S. welfare policy. Publius J Fed 29(3):51-73

Wagner A (1893) Grundlegung der Politischen Oekonomie. C.F.Wintersche Verlagshandlung, Leipzig

Waldo T (1970) A computer movie simulating urban growth in the Detroit region. Econ Geogr 46(2):234240

Yilmaz Y, Hoo S, Nagowski M, Rueben K, Tannenwald R (2006) Measuring fiscal disparities across the U.S. states: a representative revenue system/representative expenditure system approach-fiscal year 2002. Occasional Paper, No. 74, The Urban Institute, Washington, DC 